Prefacio

\title{
La dinámica superficial terrestre en países hispanoparlantes
}

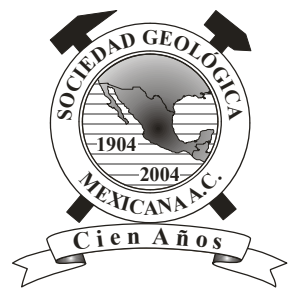

\author{
Miguel Castillo ${ }^{1}$, Esperanza Muñoz-Salinas ${ }^{1}$ \\ ${ }^{1}$ Instituto de Geología, Universidad Nacional Autónoma de México, Ciudad Universitaria, C.P. 04510, México, D.F.
}

La dinámica superficial del relieve continental está controlada por diversos procesos como son los tectónicos, volcánicos, fluviales, glaciales, eólicos, de remoción en masa y litorales. Por lo tanto, las investigaciones sobre los procesos superficiales son el objeto de estudio de varias Geociencias; no obstante, la gran mayoría de éstos son estudiados por la geomorfología. Desde mediados del siglo XX, los estudios de la dinámica superficial se han incrementado de forma notoria y la necesidad de profundizar en dichos estudios ha sido tal, que en la actualidad existen diversas revistas científicas especializadas para cada uno de los procesos mencionados arriba. De forma particular, las investigaciones de la dinámica fluvial y aquéllas orientadas a comprender y delimitar procesos superficiales que ponen en riesgo a las poblaciones, como los deslizamientos, han recibido mayor atención. Frente a las evidencias que existen sobre un posible cambio en las condiciones climáticas por causas antrópicas, el reto al que se enfrentan los estudios de dinámica superficial es comprender y responder a los posibles efectos de los procesos superficiales como consecuencia de los cambios en las condiciones climáticas globales y su posible repercusión en las actividades humanas. El estudio de los peligros naturales es, en este sentido, uno de los temas prioritarios dentro de las Geociencias.

La geomorfología está experimentando una revolución gracias a la incorporación de nuevas técnicas de fechamiento como son el uso de los radionucleidos cosmogénicos terrestres y la luminiscencia óptica estimulada. Estas técnicas geocronológicas han permitido batir un record en la medida del tiempo que va de la centena de miles de años hasta la unidad de millón de años. Estas técnicas están haciendo posible que se conozca con más detalle la temporalidad de los procesos superficiales y sus tasas de cambio. No obstante que los estudios en dinámica superficial han ido en aumento durante las últimas décadas debido a su aplicabilidad social, todavía existen zonas de la superficie terrestre de las cuales no existe información sobre los distintos procesos superficiales. Es por ello que los estudios geomorfológicos necesitan cubrir desde la información de base, como es la cartografía, hasta el nivel de cuantificación, para proporcionar edades y tasas de cambio y, en la medida de lo posible, pronosticar la frecuencia y magnitud de los diversos procesos superficiales.

En este número especial, que lleva por título "Dinámica superficial terrestre" se presentan nueve contribuciones de la geomorfología realizadas en Argentina ( 2 estudios), España (1 estudio) y México (6 estudios). En el número se abordan distintos temas con como son la geomorfología tectónica (Perucca y Vargas), la cartografía geomorfológica de zonas kársticas (Durán et al.), la geomorfología fluvial de planicies (Solís-Castillo et al.; Neri-Flores et al.) y de zonas de montaña (Andrés de Pablo et al.; Esper-Angillieri y Perucca), los procesos de ladera (Legorreta-Paulín et al.; Aceves-Quesada et al.), y la aplicación de técnicas de frontera en los estudios de dinámica fluvial (Muñoz-Salinas y Castillo). Es de resaltar que, del total de los trabajos compilados, el $40 \%$ pertenece al área de la geomorfología fluvial. La importancia del estudio de los procesos fluviales no sólo se ve reflejada en la diversidad de ambientes donde se llevan a cabo las investigaciones, también es consistente con una tendencia a nivel global por este tipo de estudios. En el total de artículos publicados en las revistas especializadas en geomorfología, como son Geomorphology y Earth Surface Processes \& Landforms, el tema de los procesos fluviales sobresale con respecto a otros temas (Figura 1).

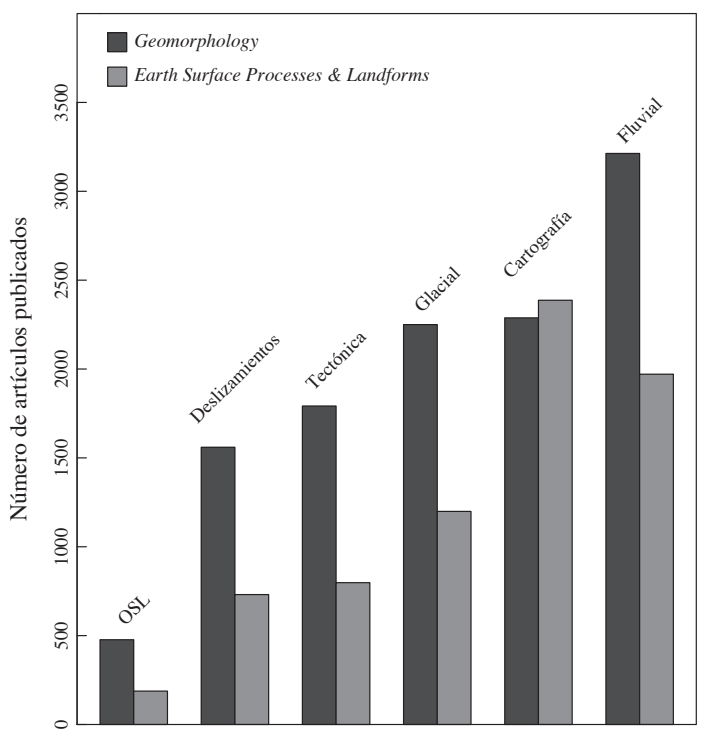

Figura 1.Artículos publicados en revistas especializadas en geomorofología. 
Los trabajos compilados en este número denotan el interés que existe en varios países hispanoparlantes por conocer y comprender los distintos procesos superficiales. Cabe mencionar que aun falta por incorporar las técnicas más recientes de dataciones para cuantificar los distintos procesos geomorfológicos, y la tarea será ardua en muchos de los casos, ya que en algunos sitios no existe la información de base. Esperamos que este número especial sea el punto de partida para que la comunidad geomorfológica en los países hispanoparlantes hagan un esfuerzo por comunicar los resultados de sus investigaciones sobre los procesos superficiales hacia otros países.
Miguel Castillo Esperanza Muñoz-Salinas 